\title{
Defining the Explicanda in the 'West and the Rest' Debate: Bryant's Critique and its Critics
}

MARK ELVIN

\section{Background Considerations}

I et me begin by putting some cards on the table. My perspective is that of someone trained more than forty years ago in western European history, but who has since worked almost entirely on the history of China, primarily from sources in the original language but almost always within an explicitly or implicitly comparative framework. I wrote my doctoral thesis on the first functioning formally, that is electorally, democratic institution in China. This was the city council of the Chinese part of Shanghai from 1905-1914. I spent a lot of time looking for elements of proto-democracy in late-imperial China, and found them to be real and interesting, but late, and slight in comparison to the ideas and pressures emanating from the modern European presence in China (Elvin $1967 ; 1968 ; 1996)$. After that I turned mainly to other aspects of premodern China, and began by contributing to the upward re-evaluation of the Chinese technology and economy of the medieval and late-imperial periods in which Jacques Gernet, Joseph Needham, Robert Hartwell, and others led the way in the West (Elvin 1972; 1973a; 1975a; 1977; 1995a; 1996). My own particular role was to re-analyze and reformulate the rich empirical work of the two generations of Japanese scholarship on which a large part of this re-evaluation now ultimately rests. Names like those of Katô Shigeshi, Amano Motonosuke, Miyazaki Ichisada, Sudô Yoshiyuki, Yabuuchi Kiyoshi, Shiba Yoshinobu and other major figures from Japanese sinology dealing with economic and scientific themes in Chinese history are a currently nearly forgotten part of the bedrock of our current understanding, both 'orthodox' and 'revisionist,' however these slippery terms are interpreted.

I spent the years from 1990 through 2002 mostly working on the environmental history of China (Elvin 1993b; 1995a; 1995b; 1998a; 1998b; 2002a; 2002b; 2003; 2004a). To some extent I thus lost the thread 
of the rapid developments in world social and economic historiography during these years. So I am out of date in this regard. At the same time, I am perhaps slightly ahead of it with respect to the history of the environment, which only plays a limited part in the themes tackled by Joseph Bryant in his critique, and Jack Goldstone, and Rosaire Langlois in their commentaries. Environmental history is, however, important in providing a crosscheck on many ideas developed by economic and sociological historians (Elvin 1993b; 1998b; 2002a).

I think that the issues forcefully, and at times brilliantly, raised by Bryant, together with the ripostes of his two critics, can lead to progress in clarifying what it is that we should be trying to explain, the key explicanda of the debates about the West and 'the rest'. ${ }^{1}$ It is worse than useless to develop theories to explain what, so far as careful scholarship can tell us, has not been the case. (Put another way, the reconstruction of the factual 'stories' to the extent our knowledge allows is still of primary importance, even if we are more conscious than in earlier days of the many-layered epistemological obstacles that can be involved. ${ }^{2}$ ) This is not just a truism. One of the long-term problems of comparative social history in this area has been the serious, and often avoidable, empirical errors made in the past regarding China even by such giants of the field as Max Weber and Fernand Braudel (Elvin 1983b; 1984; 2002c). The unsentimental clarification of what it is that actually needs to be explained is the initial duty both of the general theorist and the specialists who supply the more detailed analyses on which wider formulations are based.

1. Double quotes are used throughout only for direct identified citations. Single quotes are used for all other functions.

2. I hope Dr Langlois will forgive me using as an example of this his reference to the Taiping Tianguo, the 'Heavenly Kingdom of Great Peace,' in the middle of the 19th century. He mentions it in order to question what he sees as the erroneous view that China was "behind the West in its desire for freedom and democracy." He does not mention that the movement, led by the self-styled 'younger brother of Jesus Christ' was directly inspired by a Christian missionary tract, and that its socio-political modernization program formulated late in its history, which did indeed contain some democratic elements but was nearly totally unimplemented, was shaped by direct contact with the missionaries. It is doubtful how far ordinary Chinese who followed its theocratic leaders, inspired by trancelike divine visions, were motivated by a desire for 'freedom' in the modern sense, let alone 'democracy.' The creed of the formative phase of the Taiping movement was a Christian-Confucian synthesis, driven by the demonization of the Manchus, plus a passionate demolition of traditional polytheistic religion and its shrines. This was accompanied by an insistence, implemented to some extent, on the equality of the sexes, and the usual hopes of landholding reform. See Jian Youwen (1958) and most of a large later literature in Chinese and English. 
In particular, it is necessary to take a cool and unemotional look at western imperialism and colonialism. Both imperialism and colonialism have been common in the long sweep of human history. China, a nonwestern empire of long standing (Blunden and Elvin 1983a; 1998), was still itself engaging actively in imperialism on a substantial scale in the 18th century (Perdue 2005), and even in the later 19th, with the reconquest of eastern Turkestan (Blunden and Elvin 1983a; 1998). Western imperialism and colonialism are only significant, and comprehensible, in the wider context of the burgeoning domestic technological and organizational prowess in the West that permitted the long-range sustained projection of power overseas in a globally unprecedented fashion, and in the productive domestic use that was made of the resources so obtained or released. Uncontextualized econometrics (and I like good econometrics) are of limited meaningfulness in appraising what imperialism and colonialism may or may not have contributed to capital formation and growth in the West. Bryant handles this dimension with the appropriate sangfroid.

In the other pan of the conceptual balance needed here to weigh these issues, we should put the fact that China absorbed a massive quantity of New World silver via the Manila galleon trade, without this transforming its economy (Flynn and Giráldez 2000; 2002 ). It produced no basic transformation, though it seems to have made a major contribution to averting a liquidity crisis. China had been traumatized by earlier experiences with inflation caused by state-issued paper fiduciary money; and accessible Asian sources of copper and silver were inadequate on their own for the buoyant functioning of such a huge system, in spite of important imports of both at various times from Japan, and later even silver from Vietnam. ${ }^{3}$ It is also unlikely that the largely silver-based taxation system of the Qing could have operated without the New World inflow of bullion (Nishimoto Mio:1997:ch. 13).

There are almost certainly elements in the psychology of some 'revisionist' writers of a humanly admirable sympathetic effort to compensate for what was almost always a traumatic cultural shock for those on the receiving end of western imperialism (Elvin 1997:ch. 3; 1999). Empathy is crucial in most history writing, but sympathy is not a substitute for scholarship.

At the same time, there is one respect in which I would be happier to see the discussion presented in a rather different perspective. It is one that - with two reservations - has more in common with Goldstone's view than Bryant's. Regarding this preferred perspective, I have slowly come to the view that the most crucial dividing line of the multifaceted history

3. There is a useful summary table of Qing China's silver imports on p. 191 of Nishimoto Mio (1997). 
of modern European societies relative to that of the rest of the world is the often indirect, but almost invariably powerful, impact of what was - in its immediate, though not its remoter origins - at first European modern science. It was modern science that turned what might have been a relatively brief 'efflorescence' of 18th and early 19th century Western technological, economic, and military advantage into a process that created the runaway dynamism that has been the hallmark of economic 'modernity.' It did this by incorporating the ever-continuing advances of science into the means of production, and other technologies, such as that of warfare. And it did this in an increasingly routine fashion.

Jack Goldstone was the first to introduce the term 'efflorescence' into this discussion, and show its analytical usefulness in contrasting what happened under the Song in China with the sustained process of changes that increasingly characterized Europe after the mid-18th century (Goldstone 2002). I came to my position regarding the key role of 'modern' science in driving 'modern' economic growth mainly through Simon Kuznets' original formulation of the point in the 1960s. Kuznets took the incorporation of modern science as the defining characteristic of 'modern economic growth.'

The distinction between 'premodern' and 'modern' technological capacities was at the heart of why final-phase late-imperial Chinese farming was in some respects caught in what Radha Sinha and I called a 'premodern high-level equilibrium trap' (Elvin 1972; 1973a; 1975a; 1996). Improved methods not based on science were giving sharply diminishing returns by this time. Other types of increased inputs like a greater usage of land (notably in the uplands, often only for temporary farming), and of labour, probably including an expanded female participation in intensive agricultural tasks (e.g., Elvin 2004a, ch. 7 on Jiaxing), likewise had limits that were making themselves felt. Effective access to products based on modern chemical science like the artificial fertilizers based on the work of the great chemist von Liebig (1803-1873) could have broken through the premodern constraints by sharply lifting the Chinese agricultural production function (Wagner 1926).

In order to meet the demand that I would anticipate from readers at this point for a definition of 'modern' in the scientific context, I would argue that Alastair Crombie's view that it essentially lay in the gradual fusion of six, originally largely independent, styles of scientific thinking, and the resulting synergies from this fusion, offers a workable foundation (Crombie 1994; Elvin 2004c). ${ }^{4}$ For over 300 years, until modern sci-

4. These are, stated briefly, (1) postulational (canonically, that in Euclid's Elements), (2) experimental, (3) hypothetical modelling, (4) taxonomical, (5) probabilistic, and (6) historical (as in the reconstruction of Indo-European 
ence became more and more œcumenical (in Joseph Needham's phrase), it is the manifest exceptionalism of European science - in some ways an extraordinary lusus Naturae at the heart of modern history - that is Exhibit A in the case against most broad-brush 'revisionism.' It cannot be matched elsewhere in the world in these centuries. When eventually it is matched here and there, in Japan foremost, and in India perhaps next, the science is indisputably the offspring of a European parentage.

While Goldstone and I agree strongly on the top-level formulation, we differ on two second-level but still serious issues. I think that modern science was a general European, not, as he tends to argue or imply, just an English, creation. In my view, it both had deep medieval roots, and advanced on a very wide front, and not just in physics (Crombie 1994). ${ }^{5}$ I hesitate to cross swords with Goldstone, who was originally a research physicist, on the history of his own first discipline, but surely even at the height of Newton's eminence and the two following generations there were major mathematical physicists doing decisive work on the Continent. One thinks at once of Huyghens and his wave interpretation of light, ${ }^{6}$ and then the Bernouillis, on down to Euler and Legendre, who transmuted the formulation given by Newton into the more modern terms of energy, and the initial elements of action theory. There was - surely - enough historical momentum by this time to justify putting a low probability on its chances of being stopped dead in its tracks by any of the likely counterfactual political contingencies.

I also think that Goldstone overplays the applicability here of his highly useful earlier distinction between (1) robust and (2) critical or contingent causation. The canonical image of the latter type is that of a sphere momentarily balanced on the knife-edge of a crest running between two widely separated valley-floors, in such a way that an arbitrarily small nudge from this or that direction will send it rolling down into an eventual equilibrium position on one side or the other. But it is necessary to remember that the very nearly stable valleys have, at any

linguistics, and, later, evolution theory). For necessary further refinements I would ask those interested to look at the two lectures I gave on the topic at the Collège de France in 2005 (Elvin 2005a).

5. Gaukroger 2006 is, in its author's words on p. 195, an account of "how the new natural philosophies bec[a]me inserted into European culture in the sixteenth and seventeenth centuries." It is hard, reading his pages, to imagine it being, at the end of this, wholly channelled into intellectual dead-ends - of which there undoubtedly were some.

6. I am well aware that Newton is not to be regarded as espousing a simple particle theory, but had developed the elements of what, with a good measure of hindsight, is hard not to see as the rudiments of a dual wave-particle approach. See the introductions to Newton (1952 [1704/1730]). 
particular moment, to be historically given. The choice is never between arbitrary valleys. History also deals essentially with systems, not single particles obeying quantum mechanics as he suggests, or simple spheres following Newtonian ones. A better image might be the switching on of a previously dormant gene in a particular context by a mutation in the epigenetic system. The organism that is affected will behave somewhat differently afterwards, but it is overwhelmingly of the same nature as it was before. To call into doubt the robustness ${ }^{7}$ of modern science by the later 17 th century seems to be so exceptional a view that it needs exceptional evidence and force of argument. ${ }^{8}$

There are important corollaries of the science-based point of view. Such generation-old questions as the possible role of 'industrialization before industrialization' in the path to economic 'modernity' lose significance for the determination of critically indispensable circumstances, though retaining some measure of importance for the identification of generally facilitating conditions (see Kriedte et al. 1982, and also the later literature too extensive to list here). Inadequately argued suppositions about the answers applicable to this particular controversy underlie many 'revisionist' assertions of the quasi-parity between late-imperial Chinese and early modern European economic history (as Bryant rightly points out). The perspective that I find most persuasive, however, reduces this particular debate, not to a null, but to a secondary status.

An aspect that is these days invariably ignored is that late Song and Yuan China had already invented simple multispindle water-powered spinning and silk-twisting machinery, and then abandoned it by the first half of the Ming. Why was it not revived or reinvented later, if there really were proto-industrial tendencies stirring? This question acquires more force when one recalls that simpler twisting machines with multiple spindles moved together by a single source (using a transmission belt) were being used in Qing times, but do not seem to have inspired any attempt to move from machine-twisting to machine-spinning proper (Elvin 1972; 1973b). ${ }^{9}$

7. 'Robustness' indicates the quality of a state of affairs defined by the property that variations in the settings of its parameters will produce only disproportionately small differences in the way in which it subsequently develops. Like 'criticality' it can only be attributed hypothetically to historical cases.

8. To give a recent example, although Gaukroger (2006) stops at the year 1685, there is no hint that I can detect in his work implying that the long-term future of science was in a state of perilous uncertainty at this point.

9. Multispindle spinning-wheels were used in parts of Jiangnan, but were a technological dead-end as they required exceptional dexterity to operate. Elvin (1973b) has diagrams. 
Overall, my personal understanding of the late-imperial Chinese economic system was that its most important feature was the further development of the interlocking of its various parts. This process connected ever more tightly a continuing agricultural intensification - notably in the greater use of multiple cropping, and intercropping, rotations, and new inputs - with more densely packed annual timetables of rural work, and with numerous domestic and local by-employments, especially handicrafts. This gave the system a higher degree of resilience, and stability. The price was, of course, the increased interdependence and cross-subsidy of its parts. The effect of virtually every small improvement that was adopted at all widely in Qing technology — and there were many - seems most plausibly understood as stabilizing rather than disrupting this system. Such a perspective also renders intelligible the deep resistance of the greater part of China's economy to change even once more modern technology began to be available, discussed later.

Finally, to sum up a general impression of the controversy so far, as seen from my particular point of view, Bryant's overview of the conflict between the 'revisionists' and the two more 'orthodox' traditions of (1) mainstream European, and (2) mainstream sinologically based scholarship, regarding the position of Europe relative to China seems to me to embody, on balance, a generally sounder grasp of the relevant underlying historical realities, both European and Chinese, than do those of the scholars whom he criticizes. For example, the characterization by Goldstone of the late Ming and early Qing periods as having witnessed an agricultural "revolution" seems to me overstated, for reasons given in the preceding paragraph. For the term to make sense, a 'revolution' must trigger a basic and perduring change in a system. The introduction of certain spring crops like colza as additional crops in rice-paddies (a point established mainly by Kawakatsu Mamoru) was, for example, a significant increase in intensification in this period, but not a fundamental change in the system (Elvin 2004:ch. 7 on Jiaxing). ${ }^{10}$ I argued a generation ago that changes like these were most likely to have had the effect of helping stabilize the system in the context of a serious potential destabilizing factor, namely the (almost) steadily ever-growing population, rather than of starting a radical transformation (Elvin 1975a; 1996).

I will also make some modest criticisms of Bryant at various points in what follows. In principle, I would, of course, want in addition to include in this evaluation, as Bryant does, a consideration of the specialist scholarship on the other major late premodern non-European civilizations in the overall analysis, especially the Islamic world and India; but on these I am much less qualified to speak. I will therefore say nothing

10. See also Elvin 1973a on the earlier medieval revolution in farming. 
on them here, though I have risked commenting on them in the past (Elvin 2004d; 2004e; 2005b.).

\section{The SubtLety of the Explcanda}

It is only by a razor-sharp refinement of our understanding of key facts that one can generally hope to have a chance of teasing out the crucial differences that made something possible or not, and hence discriminate between generally facilitating conditions and critically indispensable circumstances.

This can be illustrated with a concrete example. Later 16th century China - at its exceptional best - could produce correct scientific results based on quantified data derived from careful experimental observation and expressed in mathematical form: a case in point here is the system of equal temperament tuning for both string and wind instruments invented by Zhu Zaiyu, and expressed in terms of the twelfth roots of 2 for string lengths and twenty-fourth roots of 2 for tube diameters (Elvin 2004c). Zhu's results were published in printed form. It could not, however, produce a socio-intellectual system that regularly generated, disseminated, criticized, transmitted, and improved such results (the reconstruction of historical phonetics being the one exception). The distinction is a fine one, but completely critical. Any persuasive theory that claims to explain the origins of modern science must be able both to explain why China could get this far and yet no further, as well as why the West could and did. To date no one has, in the main because there is still a poor appreciation of the real nature of the challenge (Elvin 2004b; 2005a). ${ }^{11}$

Second, 'revisionism' has, in some cases, been the driving force behind useful new research. An illustration is Qing population dynamics, where James Lee and his collaborators have been concerned to show that late-imperial China was not 'Malthusian' in the sense that they maintain there must have been controls on births of some sort limited reproduction within marriage. Why? Let us turn up the analytical focus a little for a moment.

Speaking with respect to the lower Yangzi valley in the later 18th century, it would seem little more than common sense to conclude that some spacing of births had to have occurred within marriage, assuming the normal range of female age-specific fertilities, since female marriage here was virtually universal, and early. There was a tight distribution around a mean western age of 17 years, with a sample standard deviation of 1.99 (Elvin, Fox, and Wen 2007).

11. This is the one central analytical flaw in Gaukroger (2006), which is otherwise something of a masterpiece. 
Female expectation of life at birth was 27.2 years if infanticide is treated simply as 'mortality.' If a rate of 11.5 percent for infanticide is assumed on the conservative basis of restoring parity in first-year mortality between girls and boys, then the intrinsic e(0) female rises to a level of 28.5 years. Into this picture we plug our finding that the gross reproduction rate (GRR) for actively married women was only 2.45 girl babies. How did we reach this last result?

Our data are incomplete, and adjusting for the gaps is the tricky bit, but in essence we progressively improve the determination of a demographically internally consistent model that matches all available patchy sets of data. The procedure requires repeated adjustments of the parameters. The main line of thinking for the GRR component goes as follows. We start with a template of age-specific fractional rates of birth for girls (based on recent world-wide empirical information) that gives us the female births needed for the exact replacement of a female cohort in the absence of any female mortality prior to age 50. The sum of these, or GRR, $=1$, by definition. We then add in our lower Yangzi valley mortality: the GRR female in a stationary population is the multiplier for these age-specific birth rates needed for real-life mortal women in a given cohort during the childbearing ages to ensure that the total number of woman initially born in that cohort is, as before, exactly replaced by the births of girls to the mothers in that cohort. This curve is mainly shaped by the level and pattern of mortality, showing the effects of the loss of the women who will have been removed from the cohort before or at some time during the age-span of childbearing. We then get closer to reality in specific social terms for the lower Yangzi valley in late-imperial times, and further add in the requirement that to be qualified to bear a child a live woman has also to be married or remarried to a live husband. This gives us the GRR female. It can be multiplied by a preferred sex ratio at birth to yield the parallel one for men. We have used an SR of 0.5133 , which is a middle-of-the-road estimate. The reconstruction yields a mean total of marginally over 5 children born per live, actively married, woman born into the original cohort. To conclude, it would be extraordinary if the figure could have been this low without significant limitation of births within marriage given general female marriage clustered around age 17 (Elvin, Fox, and Wen 2007).

Thus, even with an expectation of life at birth several years below the minimum of the range that Lee et al. propose, their general argument against Malthusianism can be confirmed by using quite different data and methods from theirs. Our mortality figures also move closer to those of the revisionists' once one reaches the expectancies of life above 10 or 15 , and, putatively, closer still when one takes into account probable re- 
gional variation. The data of Lee et al. are biased towards more northern populations of China, and both indigenous tradition and modern analysis hold that levels of mortality were higher in the south from where we take our data. ${ }^{12}$ On the other hand, our sample is to some degree biased towards the better-off members of society, so our expectancies are probably an upper bound for the lower Yangzi population as a whole. ${ }^{13}$

Lee et al., are probably mistaken on some specifics, however, if they are taken as applying to the lower Yangzi valley. They argue that in lateimperial times childbearing within Chinese marriage was characterized by (1) late starting, (2) long spacing, and (3) early stopping This is fairly certainly demonstrably wrong as regards (1) in the light of our data for the number of sons surviving to women both after a given number of years of marriage, and at a given age. Starting was fast, and the reconstructed curve of cumulated births ( $y$-axis) by unit of time ( $x$-axis) always convex over the span of ages covered by our data, namely up to approximately age 29. As regards (2), they are right. As regards (3), the least important aspect, we are not in a position to say anything definitive, either for or against, though we incline - for any plausible definition of 'early' - toward being a little dubious, but are not dogmatic about it.

There is the additional factor that there were also very substantial variations from one county-sized or prefectural-sized locality to the next. The gap was around 13 years for expectancy of female life at birth as between the longest- and shortest-lived areas in the lower Yangzi. This makes it risky to talk of any single 'Chinese' demographic pattern at this time. Interestingly, of the major localities covered in the study, the one with the lowest expectancy of life at birth was also one of the most 'advanced' in late-traditional economic terms, namely Jiaxing prefecture. If some sort of modern economic growth was on its way here, then the conclusion might have to be that that the 'sink of mortality' situation

12. Thus in the mid-19th century Chinese anthology of verses on aspects of everyday life, The Qing Bell of Poesy, p. 646, one finds Zhang Yun'ao peddling this commonplace:

Up in the northern regions, the land is cold and high,

And a man of forty years of age is thought still to be in his prime.

Humid the air in southern parts, and the terrain low-lying.

At thirty years here, a man will have started - already - on his decline.

On the Bell see Elvin (2004a). For supporting modern evidence of a difference between North and South, see Barclay et al. (1976).

13. Of course, the population in most of the Qing dynasty was growing, perhaps at roughly a third of a percent per year, but we have yet to find a rigorous way of accommodating this in our reconstruction, where the data come from a patchwork of series from different areas during overlapping but nonidentical periods, and only about a fifth of the cases have reasonably firm individual dates within these periods. 
found in many early modern European cities also applied to the Jiaing. But I am not persuaded that the premise is true.

Realistically, the first set of demographic facts that needs be explained for the limited number of areas in China about which we now know something is that of the regional and intraregional local variations. This is the immediate challenge to social, economic, and demographic historians.

\section{Some Specific Weaknesses and Strengths in the Bryant Case}

Bryant argues that "centralized agrarian empires, operating in a tributary mode of surplus extraction over peasant majorities and limited and controlled artisanal and mercantile sectors" were in and of themselves an effective barrier to economic modernization. The patchy but often impressive technical modernization of the late Tsarist empire (Blackwell 1968; Gershenkron 1970; McKay 1970; Sutton 1968) suggests that this broadly stated view may be in need of some sharpening, or even rethinking.

Per contra, there are places where Bryant's case can, if anything, be made even stronger. Two examples follow:

1. Anyone who studies the absorption of modern western mechanical engineering technology in China over the period from about 18601937 cannot fail to be struck by two phenomena.

a. In Shanghai, and to a lesser extent in a few other coastal cities with a western economic presence, the speed and efficiency with which the Chinese engineers and entrepreneurs learned and practised it successfully was breathtaking. Typically, they progressed from repairing to subcontracting, then to selective imitation, and ultimately to independent design. Almost the entire range of modern mechanical engineering technology, outside a few special areas such as airplanes and the designing of automobiles, had been mastered before the Pacific War. Shanghai today has modern technological roots that are already almost a century-and-a-half old.

b. The spread of the use of this new technology into the hinterland beyond Shanghai was surprisingly limited, although great efforts were made to promote it, including such offers by their manufacturers as free training for machinery operators (Elvin 1981; 1993a).

It is clear (1) that the presence of western businesses from many different countries in the areas conceded for foreign residence in the city provided the Chinese with an effective nonstop exhibition of technology, with opportunities for learning and collaboration, for the 
poaching of skilled labour and managers, for easier financing, and for access to the world outside; (2) that they had the needed capacities, including the business acumen and managerial skills, to profit from these opportunities; and (3) that, at the same time, there were characteristics deep-rooted in the late-traditional Chinese economic system as a whole that were profoundly resistant to change of this kind, even given that up-to-date technology was available in some Chinese brains and hands (Elvin 1981; 1993a). The riddle of what the nature of this resistance was has to be solved before anything sensible can be said about late premodern China's capacity for any possible breakthrough into economic 'modernity,' whether homegrown or borrowed. The 'revisionists' do not seem to grasp this.

My own research has only covered mechanical engineering, which I think of as the key economic sector as regards technical modernization. It is reasonable to suspect that much of what I found can be extended beyond this area. It should be said, though, that the full picture is a little subtler than the foregoing suggests. The hinterland did adopt various forms of what might be called 'traditionalmodern linkages' but these, too, like Qing technical refinements, probably had the effect in many cases of further stabilizing the old system by improving its efficiency.

There are some clues in the limits on the use of the Shanghai Chinese-made kerosene-powered pump in irrigation and machinery operation. In a few areas, where there was a need for a two-stage lift of irrigation water, or where labour was, for some reason, unusually expensive (such as Wuxi), it was adopted. Where there was a sort of early 'capitalist-style' farming organization on a scale substantially greater than the usual peasant operation (as in some areas near the coast of northern Jiangsu), it was also to be found. In other words, exceptional economic advantage or exceptional economic structure could at times override the late-traditional peasant-family economic social structure and cost-structure, but this was not the case generally (Elvin 1981). The adaptation of the institutions and conventions of business is, even in modern circumstances, still sometimes a crucial precondition for the profitable introduction of new technology. ${ }^{14}$ It may also have been significant here.

We can come at some of these issues from another angle. Some of my most recent research has been on the substantial number of poems written in late-imperial China on the topic of money and

14. A surprising, and thus doubly persuasive, example is the now ubiquitous container used for bulk road and waterborne transport (Levinson 2006). 
making profits. ${ }^{15}$ Most of them see money as central to daily life at all social levels (including beggars who are never depicted as begging for anything except coins), even if survival has often to be bought at the cost of inflicting damage on human relationships, or on Nature, or of taking hair-raising risks to life and limb. They show, at their most economically sophisticated, an understanding of how money, time, and interest are interrelated, as in some of their discussions of pawnshops. There is an acute interest in the causes behind the rise and fall of prices. Some poets are also infused with a streak of implacable economic rationalism - as in the many poems about the buying and selling of other human beings - which is abhorred by others. (But how else does a poverty-stricken father save his kids' lives in a famine?) I would be surprised if any other of the sophisticated late premodern cultures of this time had quite such an obsession with these subjects. As is well-known, the Chinese even operated systems for remitting 'spirit-cash' in advance to the other world, to be collected there by people once they had died, though these odd rituals were mocked by orthodox Confucian writers. Such points are worth mentioning here in order to illustrate the conceptual delicacy required in characterizing what is, and what is not, psychologically helpful for a European-style breakthrough to economic modernity. Are we to categorize the last-mentioned practice as a variety of religious rationalism? In general, I would argue that in this sort of discussion 'rationalism,' whatever it exactly is taken to be, is unlikely to provide a sufficiently sharply defined criterion for separating China from Europe.

2. China Proper was not 'colonized,' in the sense of being forcibly settled by large numbers of unwelcome foreign invaders. Nor was China Proper 'imperialized' in the sense of being militarily conquered and politically ruled by an outside power. There never was a western Viceroy in Nanjing (or wherever) wearing a white-cockaded hat (or whatever) and lording it benignly (of course) but severely over the 'natives.' Not even remotely, except marginally for a short period in Japanese-ruled Manchuria. Foreign investment per head in China before the Pacific War (again excepting Manchuria under the Japanese) never surpassed US\$10, one of the lowest levels in the world at this time, and most of it was concentrated in Shanghai (Hou Chiming 1965). Chinese merchants by and large stayed in control of the overwhelming proportion of China's internal trade (Murphey 1977; Motono 2000 ). What did happen is that China was humiliated

15.From the anthology assembled by Zhang (1869). 
by what can be imagined as a sort of deadly political and cultural 'negative acupuncture' - objectively small pricks but often with large effects. By the end of the 19th century, the inherited Chinese world of values and institutions had largely been devalued in the eyes of most of the educated members of the younger generation.

Part of this discrediting of the established order occurred because the imperial political system was to an exceptional degree a 'prestige structure' and its prestige largely disintegrated as the result of the 'negative acupuncture.' There was, however, more to it than this, and how this radical dislocation of the Chinese 'story' happened remains an intriguing and central question in China's modern history (Elvin 1999; 1990). For the purposes of the present discussion, what matters is that it is evident that most Chinese thinkers of the key transitional decades, roughly 1890-1920, saw the West as qualitatively and challengingly different, no matter whether they were conservatives or radicals, and no matter whether they loathed it or were inspired by it. Though their ideas were often an odd mixture of brilliance and stupidity, it is hard to see how one could argue that, in general, they were mistaken in their virtually unanimous basic evaluation of the old social and ideological patterns as being in some regards incompatible with modernization.

This point is in an interesting tension with three others of those just made, namely (1) that already soon after the 'opening' of their country to the West the Chinese had a capacity, under appropriate circumstances, rapidly to absorb and use modern economic technology, (2) that these new techniques had great difficulty in spreading anywhere where rather special conditions did not apply, and (3) the Chinese were on the whole obsessed with making money and profits, and mostly rather rational about it. But the coexistence of these points prompts one to think that there must have been some complex of socio-economic forces, interweaving with environmental factors, that made the Chinese society of late-imperial times seriously resistant to changes in the direction of economic modernization. It is not as yet clear in sharply defined detail what this complex really was, but it must, almost certainly, have been there. Put differently, in most places the difficulties arose less from the need to pay for 'progress' than of finding a way to make 'progress' pay.

In broad terms, then, what these last two sections imply comes close to what Bryant has been maintaining, namely, that it does not help our understanding of the global patterns of modern history if we try to blur the many distinctions between early modern Europe, on the one hand, 
and the other advanced premodern cultures of that time, on the other. My contribution in these off-the-cuff remarks, so far as it exists, has been to try to show that some of these distinctions were surprisingly subtle, and yet, all the same, often of long-term significance; and hence that, so far as the issues discussed in this debate are concerned, getting them into a clear focus is of fundamental importance for worthwhile theoretical thinking.

Verdict? - I think Professor Bryant has done us a serious service with his efforts.

\section{REFERENCES}

Barclay, G., A. Coale, M. Stoto and J. Trussell. 1976. A reassessment of the demography of traditional rural China. Population Index 42(4).

Blackwell, William. 1968. The Beginnings of Russian Industrialization, 1800 1860. Princeton, NJ: Princeton University Press.

Blunden, Caroline and Mark Elvin. 1983. A Cultural Atlas of China. Oxford: Phaedon.

Bryant, Joseph M. 2006. The West and the rest revisited: Debating capitalist origins, European colonialism, and the advent of modernity. Canadian Journal of Sociology 31(4):403-44.

2008. A new sociology for a new history? Further critical thoughts on the Eurasian similarity and great divergence theses. Canadian Journal of Sociology 33(1):147-164.

Crombie, Alistair. 1994. Styles of Scientific Thinking in the European Tradition. 3 vols. London: Duckworth.

Elvin, Mark. 1967. The gentry democracy in Chinese Shanghai. In Jack Gray, ed., Modern China's Search for a Political Form. London: RIIA.

1968. The Chinese democracy in Shanghai. Ph. D. University of Cambridge (Clare Hall). Microfilm available from Cambridge University Library, or the Sinological Institute, University of Heidelberg.

1972. The high-level equilibrium trap: The causes of the decline of invention in the traditional Chinese textile industries. In W.E. Willmott, ed., Economic Organization in Chinese Society. Stanford: Stanford University Press.

1973a. The Pattern of the Chinese Past. Stanford: Stanford University Press.

1973b. Mandarini e macchine. In Lionello Lanciotti, ed., Sviluppi scientifici, prospettive religiose, movimenti rivoluzionari in China. Firenze: Olschki.

1975. Skills and resources in late traditional China. In D. Perkins, ed., China's Modern Economy in Historical Perspective. Stanford: Stanford University Press.

1977. Market towns and waterways: The county of Shang-hai from 1480 to 1910. In G.W. Skinner, ed., The City in Late Imperial China. Stanford: Stanford University Press. 
1981. Making progress pay - A basic problem in China's early modernization. Symposium on the History of the Republic of China, vol 3. Taipei: KMT History Committee.

1983a. With Caroline Blunden. A Cultural Atlas of China. Oxford: Phaidon/Facts on File [USA]. Revised edition, New York: Checkmark,1998.

1983b. Warum hat das vormoderne China keinen industriellen Kapitalismus entwickelt? Eine Auseinandersetzung mit Max Webers Ansatz. Pp. 114-133 in Wolfgang Schluchter. ed., M. W.s Studie über Confuzianismus und Taoismus. Interpretation und Kritik. Frankfurt am Main: Suhrkamp. 1984. Why China failed to create an endogenous capitalism: A critique of Max Weber's explanation. Theory and Society 13(3).

1990. The collapse of scriptural Confucianism. Papers on Far Eastern History 41. (Later East Asian History. Research School of Pacific Studies, Australian National University.) Reprinted in Elvin 1996.

1993a. Le transfert des technologies en Chine avant la Seconde Guerre Mondiale. Nouveaux Mondes 2, Genève: CRES.

1993b. Three thousand years of unsustainable growth: China's environment from archaic times to the present. East Asian History 6.

1995a. With Su Ninghu. Man against the sea: Natural and anthropogenic factors in the changing morphology of Harngzhou Bay, circa 1000-1800. Environment and History 1(1).

1995b. With Su Ninghu. Engineering the sea: Hydraulic systems and premodern technological lock-in in the Harngzhou Bay Area circa 10001800. In Itô Shuntarô and Yasuda Yoshinori, eds., Nature and Humankind in the Age of Environmental Crisis. Kyoto: International Research Center for Japanese Studies.

1996. Another History: Essays on China from a European Perspective. Sydney: Wild Peony Press/Hawai'i University Press (distributors).

1997. Changing Stories in the Chinese World. Stanford: Stanford University Press.

1998a. Edited with Ts'ui-Jung Liu. Sediments of Time: Environment and Society in Chinese History. Cambridge: Cambridge University Press.

1998b. With Su Ninghu. Action at a distance: The influence of the Yellow River on Hangzhou Bay since A.D. 1000. In Mark Elvin and Ts'ui-Jung Liu, eds., Liu, Sediments of Time: Environment and Society in Chinese History. Cambridge: Cambridge University Press.

1999. How did the cracks open? The origins of the subversion of China's late-traditional culture by the West. Thesis Eleven 57.

2002a. The unavoidable environment: Reflections on premodern economic growth in China. In Liu Ts'ui-jung and Shih Shou-ch'ien, eds., Economic History, Urban Culture and Material Culture. Taipei: Academia Sinica. 2002b. With Darren Crook, Shen Ji, Richard Jones, and John Dearing. The impact of clearance and irrigation on the environment in the Lake Erhai catchment from the ninth to the nineteenth century. East Asian History 23.

2002c. Braudel and China. Pp. 225-253 in John Marino, ed., History and the Social Sciences in Braudel's MEDITERRANEAN: Sixteenth Century Essays and Studies, Sixteenth Century Journal. Truman State University Press. 
2003. Water in China past and present: Competition and cooperation. Nouveaux Mondes 12. Genève: CRES.

2004a. The Retreat of the Elephants: An Environmental History of China. New Haven and London: Yale University Press.

2004b. Vale Atque Ave: Introduction to Joseph Needham. Pp. xxiv-xliii in Kenneth Girdwood Robinson, ed., Science and Civilisation in China, 7. II. Cambridge: Cambridge University Press.

2004c. Some reflections on the use of 'styles of scientific thinking' to disaggregate and sharpen comparisons between China and Europe from Sòng to mid-Qing Times (960-1850 CE). History of Technology 25:53103.

2004d. Comment on 'The political pattern of historical creativity: a theoretical case' by Jean Baechler. Pp. 31-35 in Peter Bernholz and Roland Vaubel. eds., Political Competition, Innovation and Growth in the History of Asian Civilizations. London: Edward Elgar Publishing.

2004e. Comment on 'Islamic statecraft and the Middle East's delayed modernization' by Timur Kuran, Pp. 200-203 in Peter Bernholz and Roland Vaubel. eds., Political Competition, Innovation and Growth in the History of Asian Civilizations. London: Edward Elgar Publishing

2005a. L'esprit scientifique dans la Chine impériale au début du XVIIème siècle. Two lectures delivered at the Collège de France. On DVD.

2005b. Social rights to the use of nature: Thoughts on Gotô Akira et al., Rekishi ni okeru shizen. Environmental History (Nov.).

2007. With Josephine Fox and Wen Tzai-Hung. Project on Qing Dynasty Population Dynamics (QDPD). http://gis.sinica.edu.tw/QingDemography/, or http://idv.sinica.edu.tw/wenthung/Demography. Taibei. Academia Sinica. Freely downloadable numerical data, PERL programs, and analyses.

Flynn, Dennis, and Arturo Giráldez. 2000. Money and growth without development: The case of Ming China. In A. Latham and H. Kawakatsu, eds., Asia-Pacific Dynamism, 1550-2000. London and New York: Routledge. 2002. Cycles of silver: Global economic history through the mid-eighteenth century. Journal of World History 13(2).

Gaukroger, Stephen. 2006. The Emergence of a Scientific Culture: Science and the Shaping of Modernity, 1210-1685. Oxford: Clarendon Press.

Gerschenkron Alexander. 1970. Europe in the Russian Mirror: Four Lectures in Modern European History. Cambridge: Cambridge University Press.

Goldstone, Jack. 2002. Efflorescences and economic growth in world history. Journal of World History 13(2)

2008. Capitalist origins, the advent of modernity, and coherent explanation: A response to Joseph M. Bryant. Canadian Journal of Sociology 33(1):119-132.

Hou Chiming. 1965. Foreign Investment and Economic Development in China: 1840 -1937. Cambridge, MA: Harvard University Press.

Jian Youwen [Jen [Chien] Yu-wen]. 1958. Taiping Tianguo dianzhi tongkao [Institutions of the Great Kingdom of Heavenly Peace]. Hong Kong: Mengjin shuwu. 
Kriedte, Peter, Hans Medick, and Jürgen Schlumbohm. 1982. Before Industrialization. Rural Industry in the Genesis of Capitalism. Cambridge: Cambridge University Press. (First published in German in 1977.)

Langlois, Rosaire. 2008. The closing of the sociological mind? Canadian Journal of Sociology 33(1):133-146.

Levinson, Marc. 2006. The Box: How the Shipping Container Made the World Smaller and the World Economy Bigger. Princeton and Oxford: Princeton University Press.

McKay, John. 1970. Pioneers for Profit: Foreign Entrepreneurship and Russian Industrialization, 1985-1913. Chicago: University of Chicago Press.

Motono Eiichi. 2000. Conflict and Cooperation in Sino-British Business, 1860 1911: The Impact of the pro-British Commercial Network in Shanghai. Basingstoke, UK: Macmillan (St. Antony's series).

Murphey, Rhoads. 1977. The Outsiders. Ann Arbor, MI: University of Michigan Press.

Newton, Isaac. 1704/1730. Opticks. Reprint of the fourth edition. 1952. With introductions by I.B. Cohen, Albert Einstein, and Edmund Whittaker. New York: Dover Publications.

Nishimoto Mio. 1997. Shindai Chûgoku no kachi to keizai hendô [Fluctuations in prices and the economy in Qing China]. Tokyo: Kembun shuppan.

Perdue, Peter C. 2005. China Marches West: The Qing Conquest of Central Eurasia. Cambridge, MA: Harvard University Press.

Sutton, Antony. 1968. Western Technology and Soviet Economic Development, 1917-1930. Stanford CA: Hoover Institution on War, Revolution, and Peace.

Wagner, Wilhelm. 1926. Die chinesische Landwirtschaft. Berlin: Paul Parey.

Zhang, Yingchang, ed. 1869. Qing shiduo [The Qing Bell of Poesy]. Reprinted, Beijing: Xinhua shudian, 1960.

Mark Elvin has lived in Britain, the USA, France, Scotland, and Australia. His main research interest has been premodern China, and his major books are The Pattern of the Chinese Past (an interpretation of the economic and social history of imperial China), A Cultural Atlas of China (1983/1998) with Caroline Blunden, and The Retreat of the Elephants: An Environmental History of China (2004). He has also worked on premodern Chinese science, pioneering the prehistory of probabilistic thinking in China. He retired in 2006 from a research professorship at the Australian National University, and is a Fellow of the Australian Academy of the Humanities, and an Emeritus Fellow of St Antony's College, Oxford. 
